\title{
PENDUGAAN SELANG FREKUENSI PEMBELIAN, JUMLAH PERMINTAAN DAN HARGA BELI IKAN PATIN (Pangasius sp.) DI KOTA PALEMBANG
}

\author{
Interval Estimation for Frequency of Purchases, Amount of Demand and Purchase Price of Patin Fish \\ (Pangasius sp.) in Palembang City
}

Yulia Puspita Sari dan Lia Perwita Sari

Staf Pengajar Fakultas Perikanan Universitas PGRI Palembang Email: yuliaaman91@gmail.com

\begin{abstract}
Abstrak
Permintaan Ikan Patin di Kota Palembang semakin meningkat setiap tahunnya dan merupakan produksi tertinggi di Sumatera Selatan dalam kategori ikan air tawar. Harga ikan Patin cenderung mengalami kenaikan setiap tahun dan mempengaruhi frekuensi pembelian dan jumlah permintaan Ikan Patin. Tujuan dari penelitian ini untuk menduga harga ikan patin, frekuensi pembelian pembeli dan jumlah permintaan ikan Patin di Kota Palembang. Data diperolah melalui wawancara pada pembeli ikan patin di Pasar KM 5, Pasar Cinde, Pasar Kuto, Pasar Soak Bato, Pasar Alang-alang Lebar, Pasar Satelit Multi Wahana, Pasar Jakabaring, dan Pasar Kertapati. Pemilihan sampel penelitian menggunakan metode accidental sampling, yaitu konsumen yang sedang membeli Ikan Patin yang dijumpai. Hasil penelitian diperoleh frekuensi pembelian ikan patin di Kota Palembang berkisar antara 2 sampai 5 kali pembelian perbulan, dan untuk dugaan jumlah permintaan ikan patin di Kota Palembang banyaknya antara 3,9 kg sampai $10,7 \mathrm{~kg}$ per bulan setiap pembelian. Sedangkan dugaan harga beli ikan patin di Kota Palembang adalah antara Rp.20.630/kg sampai Rp.21.670/kg.
\end{abstract}

Kata Kunci: ikan patin, penduga selang, frekuensi pembelian, jumlah permintaan, harga beli

\begin{abstract}
Demand for Patin Fish in Palembang City is increasing every year and is the highest production in South Sumatra in the category of freshwater fish. The price of Patin fish tends to increase every year and affects the frequency of purchases and the number of requests for Patin Fish. The purpose of this study is to estimate the price of Patin fish, the frequency of buyer purchases and the amount of Patin fish demand in Palembang. Data was obtained through interviews with Patin fish buyers at KM 5 Market, Cinde Market, Kuto Market, Bato Soak Market, Alang-Alang Lebar Market, Multi Wahana Satellite Market, Jakabaring Market, and Pasar Kertapati. The selection of research samples using accidental sampling method, namely consumers who are buying Patin fish found. The results showed that the frequency of buying Patin fish in the Palembang city ranged from 2 to 5 times a month, and for the estimed number of requests for Patin fish in Palembang City ranged from $3.9 \mathrm{~kg}$ to $10.7 \mathrm{~kg}$ per month for each purchase. While the alleged purchase price of Patin fish in the Palembang city is between Rp.20,630/kg to Rp.21,670/kg.
\end{abstract}

Keywords: Patin fish, range estimator, frequency of purchase, number of requests, purchase price 


\section{PENDAHULUAN}

\section{A. Latar Belakang}

Permintaan Ikan Patin di Kota Palembang semakin meningkat setiap tahunnya dan merupakan produksi tertinggi di Sumatera Selatan dalam kategori ikan air tawar (Dinas Kelautan dan Perikanan Sumatera Selatan, 2015).

Peningkatan produksi ini merupakan sebagai pemenuhan akan permintaan ikan patin yang semakin meningkat di masyarakat, khususnya di Kota Palembang sebagai kota terbesar di Sumatera Selatan. Ikan patin yang dapat diolah menjadi hidangan keluarga bahkan menjadi menu kuliner dalam berbagai cita rasa menjadikan daya beli masyarakat semakin meningkat.

Harga ikan Patin cenderung mengalami kenaikan setiap tahun (Lukas, 2012). Hal ini dapat mempengaruhi frekuensi pembelian dan jumlah permintaan Ikan Patin.

Pendugaan selang dilakukan untuk melihat pada rentang berapa nilai tertentu berada. Perubahan harga ikan patin, frekuensi pembelian pembeli dan jumlah permintaan konsumen dapat digunakan sebagai acuan bagi pembudidaya dalam peningkatan produksi ikan patin, sehingga produsen tidak mengalami kerugian saat harga meningkat dan frekuensi pembelian dan permintaan sedang menurun.

Melihat fenomena tersebut penulis tertarik untuk melakukan penelitian dengan judul: Pendugaan Selang Frekuensi Pembelian, Jumlah Permintaan dan Harga Beli Ikan Patin (Pangasius sp.) di Kota Palembang.

\section{B. Rumusan Masalah}

Berdasarkan uraian tersebut maka permasalahan yang teliti adalah berapakah dugaan selang tingkat permintaan ikan patin patin di Kota Palembang berdasarkan frekuensi pembelian, jumlah permintaan dan harga beli ikan patin.

\section{Tujuan Penelitian}

Adapun yang menjadi tujuan penelitian ini adalah untuk mengetahui besarnya dugaan tingkat permintaan ikan patin di Kota Palembang berdasarkan frekuensi pembelian, jumlah permintaan dan harga beli ikan patin.

\section{METODE PENELITIAN}

\section{A. Tempat dan Waktu Penelitian}

Data penelitian diperoleh melalui wawancara langsung kepada pembeli ikan patin di delapan pasar tradisional di Kota Palembang yaitu di Pasar KM 5, Pasar Cinde, Pasar Kuto, Pasar Soak Bato, Pasar Alang-alang Lebar, Pasar Satelit Multi Wahana, Pasar Jakabaring, dan Pasar Kertapati, pada bulan Juli 2018. Delapan pasar-pasar tersebut karena termasuk delapan pasar terbesar di Kota Palembang (BPS Sumatera Selatan, 2015).

\section{B. Metode Penelitian}

Responden dalam penelitian dipilih menggunakan metode accidental sampling. Responden adalah pembeli yang sedang membeli ikan Patin, sebanyak 40 orang, yaitu masingmasing 5 orang di setiap pasar.

\section{Jenis dan Sumber Data}

Jenis data yang digunakan dalam penelitian ini adalah data primer. Data primer diperoleh dari wawancara langsung kepada responden dengan mempergunakan kuesioner. Data primer yang dikumpulkan terdiri dari frekuensi pembelian ikan patin, jumlah permitaan ikan patin dan harga beli ikan patin.

\section{Metode Pengolahan Data dan Analisis Data}

Nilai dugaan permintaan ikan Patin di Kota Palembang berdasarkan frekuensi pembelian ikan patin, jumlah permintaan ikan patin dan harga beli ikan patin maka digunakan teori estimasi (dugaan) selang.

Estimasi adalah proses yang memerlukan serta menggunakan estimator untuk menghasilkan sebuah estimate dari suatu parameter. Estimasi ialah angka atau nilai yang di gunakan untuk menaksir parameter populasi. Estimasi Selang (Interval Estimation) merupakan sekumpulan nilai-nilai sttitik sampel dengan range atau interval tertentu, digunakan untuk menaksir parameter populasi serta diharapkan nilai parameter terletak pada interval nilai-nilai itu (Harinaldi 2005).

Perhitungan dugaan selang menggunakan tingkat kepercayaan 95\%, dengan peluang data mengikut distibusi normal $\mathrm{Z}$ yang secara matematis dirumuskan sebagai berikut:

$$
P\left[\overline{X-Z_{0.5} S / \sqrt{n}<\mu<X+Z_{0.5} S / \sqrt{n}}\right]
$$

Hasil perhitungan dari dugaan selang tersebut akan menghasilkan suatu interval nilai dugaan dari variabel-variabel yang akan diduga.

\section{HASIL DAN PEMBAHASAN}

\section{A. Dugaan Selang Permintaan Ikan Patin di Kota Palembang berdasarkan Frekuensi Pembelian}


Dari hasil penelitian mengenai frekuensi pembelian ikan patin yang dilakukan oleh peneliti di beberapa pasar tradisional Kota Palembang diketahui bahwa frekuensi pembelian ikan patin oleh pembeli bervariasi. Dari data yang diperoleh frekuensi pembelian ikan patin oleh pembeli rata-rata sebanyak 3 kali. Sehingga dengan mengikuti distribusi sebaran normal diperoleh dugaan selang $\mathbf{P}[\mathbf{2 , 8}<\boldsymbol{\mu}<\mathbf{4 , 9})$ sehingga dapat diartikan bahwa dengan tingkat kepercayaan $95 \%$ bahwa rata-rata frekuensi pembelian ikan patin oleh pembeli di Kota Palembang berkisar antara 2 sampai 5 kali pembelian.

\section{B. Dugaan Selang Permintaan Ikan Patin di Kota Palembang berdasarkan Jumlah Permintaan}

Dari hasil penelitian mengenai jumlah permintaan ikan patin yang dilakukan oleh peneliti di beberapa pasar tradisional Kota Palembang diketahui bahwa jumlah permintaan ikan patin tiap individu pembeli beragam. Dari data sampel yang diperoleh bahwa jumlah permintaan ikan patin rata-rata sebanyak $7,3 \mathrm{~kg}$. Sehingga dengan mengikuti distribusi sebaran normal diperoleh dugaan selang $\mathbf{P}[\mathbf{3 , 9}<\boldsymbol{\mu}<$ 10,7) dugaan yang diperoleh ini dapat diartikan bahwa dengan tingkat kepercayaan $95 \%$ rata-rata jumlah permintaan ikan patin oleh pembeli di Kota Palembang berkisar antara 3,9 kg sampai $10,7 \mathrm{~kg}$ per bulan setiap pembelian.

\section{Dugaan Selang Permintaan Ikan Patin di Kota Palembang berdasarkan Harga Beli Ikan Patin \\ Dari hasil wawancara pada responden} tentang harga beli ikan patin di beberapa pasar tradisional di Kota Palembang diketahui bahwa rata rata harga beli ikan patin sebesar Rp. $21.150 / \mathrm{kg}$. Sehingga dengan mengikuti distribusi sebaran normal diperoleh nilai dugaan selang harga beli ikan patin $\mathbf{P}[\mathbf{3 , 9}<\boldsymbol{\mu}<\mathbf{1 0 , 7 )}$. Dugaan yang diperoleh ini dapat diartikan bahwa dengan tingkat kepercayaan $95 \%$ rata-rata harga beli ikan patin di Kota Palembang berkisar antara Rp. 20.630/kg sampai Rp. 21.670/kg.

\section{KESIMPULAN DAN SARAN}

\section{A. Kesimpulan}

Berdasarkan hasil penelitian yang dilakukan maka dapat disimpulkan bahwa frekuensi pembelian ikan patin di Kota Palembang berkisar antara 2 sampai 5 kali pembelian perbulan, dan untuk dugaan jumlah permintaan ikan patin di Kota Palembang banyaknya antara $3,9 \mathrm{~kg}$ sampai $10,7 \mathrm{~kg}$ per bulan setiap pembelian. Sedangkan dugaan harga beli ikan patin di Kota Palembang adalah antara Rp.20.630/kg sampai Rp.21.670/kg.

\section{B. Saran}

Berdasarkan hasil penelitian mengenai dugaan frekuensi pembelian ikan patin, jumlah permintaan ikan patin dan harga beli ikan patin di Kota Palembang, maka saran yang dapat diberikan bagi penelitian selanjutnya yaitu sebaiknya peneliti membahas mengenai faktorfaktor yang mempengaruhi frekuensi pembelian ikan patin, jumlah permintaan ikan patin dan harga beli ikan patin di Kota Palembang.

\section{DAFTAR PUSTAKA}

Badan Pusat Statistik Sumatera Selatan. 2015. Sumatera Selatan Dalam Angka 2015. BPS Provinsi Sumatera Selatan. Sumatera Selatan.

Dinas Kelautan dan Perikanan Provinsi Sumatera Selatan.2015. Statistik Perikanan Budidaya. Sumatera Selatan.

Harinaldi. 2015. Prinsip-prinsip Statistik Untuk Teknik dan Sains. Erlangga. Jakarta.

Lukas. 2012. Analisis Biaya Produksi dan Pendapatan Budidaya Ikan Patin (Pangasius pangasius) di Kabupaten Kapuas Jurnal Hewani Tropika. 1 (1): 3639. 